\title{
Older South Sami women and men's expectations regarding home healthcare in Sweden
}

\section{AUTHORS}

TOVE MENTSEN NESS, RN, PhD ${ }^{1}$

SIV SÖDERBERG, RNT, PhD, Professor emerita ${ }^{2}$

OVE HELLZEN, RN, PhD, Professor ${ }^{2}$

\section{CORRESPONDING AUTHOR}

TOVE MENTSEN NESS Faculty of Nursing and Health Sciences, Nord University, Finn Christensens vei 17801 Namsos, Norway. Email: tove.m.ness@nord.no
1 Faculty of Nursing and Health Sciences, Nord University, Namsos, Norway

2 Department of Nursing, Mid-Sweden University, Sundsvall, Sweden

\section{ABSTRACT}

Objective: The aim of this study was to describe the views and expectations concerning home healthcare from the perspective of older South Sami women and men in comparison with each other.

Study design and methods: In this study, 56 older South Sami women $(n=31)$ and men $(n=25)$ were interviewed by telephone, using semi-structured interviews. Data was subjected to qualitative content analysis.

Results: Our results revealed both similarities and some slight differences between the male and female participants. Both male and female participants expected the same care providers over time, in addition to expecting competence. Additionally, our female participants stressed that care providers should use time in their encounters with them as care receivers. For some female participants, this was related to competence. The findings also revealed that the care providers' cultural backgrounds were of importance to both female and male participants, even if female participants preferred care providers with a South Sami background to a greater extent. The male participants stressed that having care providers with a South Sami background could be of importance, but they were more concerned about the care providers' competence in the encounters with them as future care receivers. The main findings show that older South Sami women and men mostly have similar expectations of future home healthcare.

Conclusions: Our results highlight that having the same care providers over time, with the necessary competence, is of importance to our participants. Additionally, participants prefer their care providers to have a South Sami background - although not at the expense of competence - and this was especially highlighted by the South Sami men.

Implications for research, policy, and practice: Our study indicates that, if possible, in encounters with South Sami women and men, home healthcare services should facilitate for the same care providers over time and that they should be competent, preferably of a South Sami background, and speak South Sami if the care receiver has mastered the Sami language.

Keywords: South Sami people, expectations, home healthcare, interviews, qualitative content analysis

What is already known about the topic?

- Older South Sami people want the same care providers over time, with individual adjustments and competent care providers in home healthcare.

- There are contradictions in and between older South Sami people, about having care providers with South Sami background speaking South Sami in home healthcare. 
What this paper adds

- Older South Sami women and men mostly have similar expectations of future home healthcare.

- Home healthcare services should facilitate for the same care providers over time and that these should be competent and preferably of a South Sami background.

\section{BACKGROUND}

International studies show that indigenous peoples have poorer health and social outcomes than non-Indigenous populations. ${ }^{1}$ This is, however, generally not the case in the Nordic countries, where the Sami and benchmark populations show similar overall health and distribution of health indicators. ${ }^{1}$ Somatic health among the Indigenous Sami people indicates that a majority of the Sami population experience good health, and that mortality and life expectancy are similar to those of a non-Sami population., ${ }^{2,3}$ Nurses are expected to be culturally sensitive and have cultural knowledge in encounters with patients. In order to provide primary healthcare or aged-care services to indigenous people in support of their well-being, maintaining Indigenous identity, promoting independence and delivering culturally appropriate care is of importance. ${ }^{4}$ Accordingly, to provide culturally appropriate services for Indigenous people, clear communication and cultural sensitivity training are of importance. ${ }^{5}$ However, Dagsvold, Møllersen and Blix state that clinicians' perceptions of culture decide the extent to which they can take cultural considerations about Sami patients into account. ${ }^{6}$ An important starting point in the nurse-patient encounter is a holistic perspective where cultural and ethnic aspects are taken into account. Ekman et al. attach great significance to the importance of language and the advantage that it brings if staff in elderly care and home healthcare share the patient's language and culture. ${ }^{7}$ For example, having Swedish as a second language and losing contact with their own culture and language makes older people extra vulnerable and isolated. ${ }^{8}$ Mehus et al. found that Sami patients in encounters with healthcare professionals prefer the use of the Sami language, as this can present a confirmation of their identity. ${ }^{9}$ Bilingualism is difficult to identify, even in contexts where almost $50 \%$ of the population are Sami. ${ }^{10}$ It seems like clinicians' perceptions of culture influence how they take cultural considerations about their Sami patients into account.
The present study is part of a larger research project designed to examine the view of home healthcare from the perspective of older people with a South Sami background in Sweden. The research showed that older South Sami people wanted home healthcare to involve the same care providers over time, with individual adjustments and competent care providers. ${ }^{11}$ This corresponds well with the rest of the population in Sweden. Further, research revealed contradictions in and between participants, as they had different preferences regarding having care providers with a South Sami background speaking South Sami, despite having similar South Sami backgrounds. Additionally, the study showed that Sami food had a special significance for the South Sami people.

Ness, Hellzen and Enmarker found that older men and women may have different preferences as a result of getting older, living alone, experiencing gradually declining health and being in need of home healthcare. ${ }^{13,14}$ The oldest old men living alone and receiving home healthcare could experience loneliness, which only diminished when they received visits from family or home healthcare providers, and this entailed a desire to move to the nearest nursing home when their wife died and they needed help. ${ }^{13}$ On the other hand, the oldest old women wanted to stay in their own homes, even if their health deteriorated and they were in need of help. They did not experience loneliness to the same degree as the men when being alone, but rather experienced solitude and a desire to remain in their own homes despite declining health. ${ }^{14}$ These two studies may help shed light on the possibility that older men and women may have different preferences regarding receiving home healthcare as they get older, which is also one reason why examining possible differences between older South Sami women and men may be of interest when talking about future expectations regarding home healthcare. Thus, the aim of this study was to describe views and expectations of home healthcare from the perspective of older South Sami women and men in comparison with each other. 


\section{METHOD}

\section{DESIGN}

A qualitative method has been chosen to achieve the study aim, personal interviews were performed with the participants, and interview data was subjected to qualitative content analysis. ${ }^{15}$

\section{CONTEXT}

The South Sami population is one of several different Sami populations, and consists of nearly 2,0oo people living in the central regions of Sweden and Norway. The population has close relationships and connections across the national border, as a result of traditional reindeer migration. ${ }^{16}$ About 500-70o South Sami people in Sweden and Norway speak South Sami. ${ }^{17,18}$

\section{PARTICIPANTS AND PROCEDURE}

A purposive sample of 56 older South Sami people ( 31 women and 25 men $)$ aged from 69 to 90 years $(\mathrm{md}=74)$ participated in this study.

\section{TABLE 1. OVERVIEW OVER AGE DISTRIBUTION BETWEEN OLDER WOMEN AND MEN.}

\begin{tabular}{|l|l|}
\hline Age 69-79 & Age $80-90$ \\
\hline 24 women & 7 women \\
\hline 23 men & 2 men \\
\hline
\end{tabular}

They all came from the South Sami area in Sweden, meaning the four counties of Västerbotten, Jämtland, Härjedalen and Dalarna. All participants were living at home, some with their spouse, while others lived alone. Some participants had experiences as patients, next of kin, or healthcare providers themselves, while others had not. All participants had various earlier occupations, e.g., as reindeer herders, electricians, healthcare personnel or teachers. A written request was sent out to 189 persons, all registered on the electoral list with the Sami Parliament, and they were asked to participate in the study. To be registered on the Sami Parliament electoral list in Sweden means that each individual must meet two self-reported criteria: (A) The person must consider himself or herself as Sami and (B) any of the person's parents or grandparents must have spoken the Sami language in their home. ${ }^{19}$ The nonresponse level was high, due to the possibility that many potential participants were working with reindeer herding, as the data collection was performed during the summer. The participants who were interested in participation in the form of a telephone interview were contacted by the interviewer, and agreement on a suitable time was made.

\section{INTERVIEWS}

Semi-structured interviews were conducted over the phone with the participants during the summer of 2016 by an interviewer with a South Sami background, who could speak South Sami if preferable to the participants. ${ }^{20}$ All participants chose to speak Swedish with the interviewer. The participants were asked to describe their expectations concerning home healthcare and whether they saw it as important to have care providers with a South Sami background who spoke South Sami when offering care in the future. All participants were asked the same questions. The interviews lasted from 10 to 30 minutes, were recorded and later transcribed verbatim by the interviewer. Personal information was replaced with codes.

\section{DATA ANALYSIS}

A qualitative content analysis was performed in several steps separately for the interviews with the women and the men, using the qualitative content analysis process described by Graneheim and Lundman. ${ }^{21}$ The analysis can be described as a process of identifying, coding and categorising the primary patterns in the data. ${ }^{15}$ The analysis started with each transcribed interview, texts were read through several times keeping the aim of the study in mind in order to obtain an overall picture of the content. Next the interview texts were divided into meaning units, based on the aim of this study. Each of these units were condensed and labeled with codes based on the content. The coded meaning units were then compared, sorted and divided into categories separately for the interviews with the women and the interviews with the men (Table 1 ). ${ }^{15}$ The first author carried out the initial analysis; however, all three authors have reflected on and continuously and critically worked with the assessments until a consensus was reached.

\section{ETHICAL CONSIDERATION}

Before taking part in this study, consent was obtained from the participants and information about the possibility to withdraw at any given time was given. Moreover, the participants were guaranteed confidentiality and an anonymous presentation of the results. The study was carried out in agreement with the Declaration of Helsinki. ${ }^{22}$ The study was approved by the Regional Ethical Review Board, Umeå, Sweden (2016/33-31Ö).

\section{RESULTS}

The analysis revealed two categories for the South Sami women and two categories for the South Sami men (Table 2). In the subsequent section, the categories for the South Sami women are presented first, followed by the categories for the South Sami men, and they are illustrated with quotations from the interview texts. 
TABLE 2. OVERVIEW OF CATEGORIES CONSTRUCTED FROM THE INTERVIEWS WITH OLDER SOUTH SAMI WOMEN AND MEN

\begin{tabular}{|l|l|}
\hline $\begin{array}{l}\text { Categories for South Sami } \\
\text { women }\end{array}$ & Categories for South Sami men \\
\hline $\begin{array}{l}\text { 1. Having the same care } \\
\text { providers who have competence } \\
\text { and time to spend }\end{array}$ & $\begin{array}{l}\text { 1. Having the same care providers } \\
\text { who have competence and are } \\
\text { pleasant }\end{array}$ \\
\hline $\begin{array}{l}\text { 2. Contradictions, but } \\
\text { preferable to have a South Sami } \\
\text { background }\end{array}$ & $\begin{array}{l}\text { 2. Nice with South Sami } \\
\text { background, but more important } \\
\text { to have the right competence }\end{array}$ \\
\hline
\end{tabular}

\section{CATEGORIES FOR OLDER SOUTH SAMI WOMEN}

Having the same care providers who have competence and time to spend

Some of the women said that they did not have any specific views or expectations about future home healthcare, but other participants highlighted that they wanted the same care providers when receiving care. The reason for this mentioned most often by the women was that having the same care providers over time could represent security, and that the participants did not have to explain what they meant to several care providers, and this could entail good care:

"I want good and safe care...//... with few care providers."

Participants mentioned that future care providers should be flexible, have competence, and that the received care should be based on the care receiver's needs and clinical requirements. When talking about competence, participants did not always specify what this meant, but some discussed competence in relation to, e.g., feeling safe and using time in the encounters with them as future care recipients. They wanted future care providers to use their time properly, which could lead to greater security and the possibility to see them as care receivers:

"I want them to see all of me, and if that takes nine minutes and not seven, that's OK. I don't want them standing looking at their watch."

\section{Contradictions, but preferable to have a South Sami background}

The women stated that having care providers with a South Sami background was of varying importance, and a few emphasised that having the right competence was more important than their background. Others said that it would be nice having care providers with a South Sami background if they had the right competence.

"I hope they have the right competence. It could be nice if they have a South Sami background, but then they have to have the right competence as well, so that I can feel safe. You can get some of that safety being with someone you know."
Although some women said that it was not so important to have care providers with a South Sami background, some said that they would not demand it, and others again expressed that it was highly preferable for them to have a South Sami background. Those who wanted care providers with a South Sami background believed that they were able to understand them as care receivers much better. By being part of the South Sami culture, and knowing the codes, they would have a much better understanding, and they as care receivers would not have to explain so much, because the care provider would already know their point of view.

"Of course, I do want that (care providers with South Sami background). It would be so much easier, because I wouldn't have to explain things. She would understand just by coming through the door. You cannot get past that, that's just how it is."

When talking about the South Sami language, some stated that they themselves had not mastered the South Sami language, whilst others said that they spoke both, so they did not have to speak South Sami with the care providers, even if they thought it would be nice to speak South Sami.

\section{CATEGORIES FOR OLDER SOUTH SAMI MEN}

\section{Having the same care providers who have competence and are pleasant}

Some men responded that they did not have any specific views or expectations about future home healthcare, and said that they still felt fit. The older men expressed that they had not considered what to expect from home healthcare, if that could be relevant for them. Others who had thought about this issue said that they would prefer care providers who had personal qualities such as being helpful and having a sense of humour.

"I hope they are obliging, gentle and have a sense of humour."

In addition to these personal qualities, some participants emphasised that, if they required care, they would want to be cared for by providers with the right competence. Participants did not always specify what they meant with competence, but it was mentioned in relation to having the ability to create a relation by using, for instance, humour, and being an educated care provider. Some participants mentioned without being asked that the care provider's background did not matter when receiving care, but the care provider's competence did:

“...(I am not all that Sami).... I just want the best care provider, and where they are from doesn't matter, as long as they have the right competence. That's what matter to me."

Participants expressed views and expectations of future home healthcare where the providers were able to recognise them as care receivers, where they would not have to explain so much about their own personal situation.

"I don't want so many different people, because I want them to remember me, so they will know what I want." 
Some participants emphasised that they wanted care providers who considered their individual needs, and that the care received/given should be based on this.

\section{Nice with a South Sami background, but more important to have the right competence}

Having care providers with a South Sami background, speaking South Sami, was of varying importance to the male participants in the study. A few participants said it would be fantastic to have care providers with a South Sami background, because they would have a solid basis to understand them as care receivers (better than other care providers). Other participants said it would be nice to have care providers with a South Sami background who were fluent in the South Sami language:

"It works fine for me as it is, but it would be nice if some (care providers) could speak South Sami with me, but otherwise it works well with Swedish-speaking care providers."

Most of the male South Sami participants did not believe it was important to have care providers with a South Sami background who could speak South Sami, and this was expressed by both South Sami men who had lived close to the Sami culture and spoke South Sami themselves, and by those who had not. As one who had never thought about having care providers with a South Sami background said:

"I've been a Sami since I was born, but I've never thought about that issue. I know I have a Sami background, but I've neither lived as a Sami nor spoken the language."

Even if several respondents expressed that it could be nice to have care providers with a South Sami background, most of the men highlighted that it was more essential that the care providers were skilled, were interested, and had the right competence to care for them as care receivers:

"I wouldn't claim that that is important (having care providers with a South Sami background) - it is much more important that they are interested and have the necessary knowledge (of how to help old people)."

\section{DISCUSSION}

The aim of this study was to describe and compare the views and expectations of home healthcare from the perspective of older South Sami women and men. Because we could not find any studies focusing on older South Sami people's views and expectations of home healthcare, except for the two studies from our overall research project designed to examine the view of home healthcare from the perspective of older people with a South Sami background in Sweden, ${ }^{11,12}$ we discuss our findings in the light of general studies of Sami people's experiences and care providers in relation to healthcare services.
The results revealed that both male and female participants expect the same care providers over time, while also expecting care providers to have competence. Having expectations regarding having the same care providers over time can be linked to continuity in care. Continuity in care is seen as both necessary and highly preferable when receiving care,$^{23}$ and is connected to improvement in care receivers' functional levels and psychosocial well-being. ${ }^{24}$ Continuity is seen as a universal requirement for most people receiving nursing care, and not something that only some patient groups prefer. ${ }^{25,26}$ Therefore, there is nothing exceptional about the participants expectations when wanting the same care providers over time, which can provide continuity when receiving care. Sparbel and Anderson stress that continuity of care is considered a prerequisite of good care, ${ }^{27}$ and is strongly associated with patient satisfaction with care, ${ }^{28}$ and this is in line with our participants wanting continuity in future home healthcare. Continuity is also related to decreased hospitalisation and decreased healthcare costs. ${ }^{29}$

Additionally, continuity is related to having the right competence and amount of care providers who can carry out the care tasks in the home healthcare adequately, ${ }^{23,24}$ and then the care providers must have the right amount of time to provide the care needed. This can be related to participants wanting care providers with competence, as well as the result highlighted by the Sami women in our study, which concerned time and was spoken in relation to competence by some participants. Therefore, in order to provide continuity in home healthcare, time may be of importance, as mentioned by some of our female participants, as the care provider has to use the time needed to see the whole person receiving care. When care providers have time in their encounters with care receivers, the possibility to get to know the care receivers is enhanced, and the opportunity to provide good qualitative care is increased. McDonald et al. identified that using time in home healthcare and having the same care providers over time increases the opportunity to provide perceived good care, and to maintain continuity for both the care receivers and the care providers. ${ }^{30}$ This corresponds to the view of several of our participants in the study who saw this as an important element in future home healthcare.

The interpersonal dimension of continuity as mentioned by Gjevjon draws attention to the relationship between the care receiver and the care provider, and implies that continuity of care involves interpersonal interactions between the care receiver and one or several care providers, where one-to-one interaction represents a high degree of interpersonal continuity. ${ }^{25,26,31}$ This is in line with our results, as our participants wanted few care providers in order to experience continuity. Additionally some female participants in our study also wanted the care providers to make good use of their time in their encounters with them. Using time in their encounters in the way some female participants 
expected (entailing greater security and the possibility of being seen as care receivers) is in line with Mehus et al. discussion regarding communication in encounters with care providers. ${ }^{9}$ Mehus et al. also found that North Sami who had North Sami as their mother tongue wanted care providers to use time in their encounters so they could have the possibility to present themselves and speak in general terms about broader topics before coming to the point. ${ }^{9}$ This can be seen in connection with the results in our study as most of our female participants wanted care providers in their home to use time, even when expressing the use of 'time' in a broader perspective, and not just in relation to communication with possible care providers. Some of our female participants also related time to the care providers competence, as 'time' can be seen as the time that is required to provide good and appropriate care to the care receiver.

Another measure that can be seen as a prerequisite for good care is therefore competence, as stated by both our female and male participants. Research shows that care receivers do expect care providers to be competent when they receive care, ${ }^{32,33}$ and this is also emphasised by older persons living in their own homes.34,35 Our participants are no different in that regard, and this was something most participants in this study stressed when talking about their expectations.

Having care providers with a South Sami background was something that both female and male participants in our study preferred to some degree, even if the female participants stressed this to a higher degree than the male participants. For the male participants, the care providers' competence was given more emphasis, whilst the female participants mostly highlighted the care providers' South Sami background in addition to their competence, as the care providers' South Sami background could entail a deeper understanding of the care receivers. Mehus et al. found that Nord Sami had to act as translators for their relatives when they could not express themselves fully in Norwegian in healthcare encounters. ${ }^{36}$ Some also felt they had experienced neglect, discrimination, social isolation and disconnection from Sami culture, as their Sami background was not given sufficient consideration by the healthcare personnel. When talking about the importance of having care providers who were fluent in the South Sami language, the participants in our study did not emphasise this to the same degree, even if more of the female participants mentioned this than the male participants. One reason for this may be that the participants themselves had different levels of mastery of the South Sami language, due to earlier discrimination in conjunction with the Swedish colonisation process, where several lost their South Sami language, or it could be that the participants did not see it as an option to demand that care providers speak the South Sami language. This is in line with an earlier study by Ness, Enmarker and Hellzen. ${ }^{37}$ This means that the South Sami people are regarded as bilingual, meaning that the participants in our study are used to speaking Swedish in encounters with e.g., care providers, and have the ability to express themselves in both languages when receiving care, and therefore language issues are not a problem for most South Sami people ${ }^{12}$. Even if the importance of the South Sami language was not stressed by participants in our study, more participants expected to have care providers with a South Sami background because this could mean the care providers would have a deeper understanding of them, as they would be able to understand the codes and the Sami way of living. Mehus et al. found that Sami patients may have another way of communication, ${ }^{9}$ e.g., under-communication of their own symptoms, because they do not want to complain, and this could be in line with our results, as some participants would avoid e.g., having to explain their method of communication. In addition, Mehus et al. and Ness et al. found that care receivers feel comfortable in their mother tongue,,${ }^{912}$ and this was also mentioned by participants in this study. Some of the female participants in our study stated that they preferred care providers with a South Sami background because this could entail a deeper understanding from the care providers, and this could be in line with the results of Mehus et al., ${ }^{9}$ where care receivers could have another way of communicating in encounters with care providers.

Dagsvold, Møllersen and Blix revealed that clinicians had different preconceptions towards patients with a North Sami background in relation to the Sami patient's way of living and way of communicating. ${ }^{6}$ The clinicians assumed that the Sami patients wanted to keep their problems within the family, and that the way to communicate for Sami people meant the absence of verbal communication about some topics and indirect communication. In addition, they assumed that Sami patients were more ashamed of having a mental illness, because this was seen as a weakness within their Sami community. Notwithstanding these assumptions, only a few clinicians in the study elaborated on how their assumptions had an impact on their communication with and treatment of the Sami patients. These clinicians revealed that their assumptions about the Sami ways of communicating did not always reflect the actual experience when they met the Sami patient, and they also revealed that they did not have any discussion at their workplace regarding whether they should consider the care receivers' cultural background or not. Dagsvold et al. ${ }^{6}$ show that patients with a Sami background are different, which is also described by participants in our study as they had different expectations towards future home healthcare providers. Even if they (care receivers) do have a Sami background, having fixed assumptions as a care provider may be a negative quality, as patients are different even if they have the same cultural background. In addition, Dagsvold et al. also state that care providers must use their competence when meeting all patients, ${ }^{6}$ including patients with a Sami background, as all care receivers are different, as shown in our study. Participants in our study preferred having care 
providers with a South Sami background, but their most important consideration was still the competence of the care provider, and this was slightly more emphasised by the male participants than the female participants.

\section{METHODOLOGICAL CONSIDERATIONS}

This study focused on describing differences in the expectations of older South Sami people in Sweden. One strength of the study is that it has the opportunity to provide an insight into how equally/differently men and women can view a particular phenomenon. The intention is not to generalise the results, but only to highlight the complexity of the expectations of older southern Sami in Sweden with regard to home healthcare. This study can be used for the development of competence regarding home nursing care in relation to older South Sami people and the development of nurses' competence when encountering ethnic minority groups in home nursing care. Fifty-six people were interviewed by telephone, and this could, according to Novic, ${ }^{38}$ be seen as a disadvantage when compared to face-to-face interviews. However, telephone interviews were seen as preferable when participants were hard to reach. We also preferred having an interviewer with a South Sami background to conduct the interviews because this, among other reasons, can improve the rigorousness of qualitative research when interviewing participants with a South Sami background, due to consideration of language and communication issues. The interviews lasted from 10 to 30 minutes, and this can be seen as a limitation where important concepts such as competence could only be elaborated on if the participant themselves initiated the discussion.

\section{CONCLUSION AND IMPLICATIONS FOR PRACTICE}

Our results revealed both similarities and some slight differences between the male and female participants. Both male and female participants expected the same care providers over time, in addition to expecting competence. Additionally, our female participants stressed that care providers should use time in their encounters with them as care receivers. For some female participants, this was related to competence. The findings also revealed that the care providers' cultural backgrounds were of importance to both female and male participants, even if female participants preferred care providers with a South Sami background to a greater extent than the male participants. The male participants stressed that having care providers with a South Sami background could be of importance, but they were more concerned about the care providers' competence in the encounters with them as future care receivers.
Our study therefore shows that male and female participants have mostly similar expectations to future home healthcare. Having the same care providers over time, and who have competence and preferably a South Sami background, is of importance to our participants. The results indicate that the participants prefer care providers who represent continuity and competence, as this will ensure they receive the best possible home healthcare. Additionally, they prefer their care providers to have a South Sami background, as long as this is not at the expense of competence. Our study therefore indicates that, when possible, in encounters with South Sami women and men, home healthcare services should facilitate for the same care providers over time, namely those with competence and, preferably, a South Sami background.

Our data are based solely on our participants' personal expectations, and our aim is not to generalise the experience of other Indigenous populations. Our results do however stress the importance of cultural sensitivety and the importance of having the same cultural background as the care receivers when providing care as healthcare personel.

\section{Conflict of interest: None.}

Acknowledgement: We want to thank our participants for participating in this study.

\section{REFERENCES}

1. Anderson I, Robson B, Connolly M, Al-Yaman F, Bjertness E, King $A$, et al. Indigenous and tribal peoples' health (The LancetLowitja Institute Global Collaboration): a population study. Lancet, 2016; 388(10040):131-157.

2. Storm Mienna C, Axelsson P. Somatic health in the Indigenous Sami population - a systematic review. Int J Circumpolar Health. 2019; 78(1) Available from: https://doi.org/10.1080/22423982.2 019.1638195

3. Gerdner A, Carlson P. Health and living conditions of Samis compared with other citizens based on representative surveys in three Swedish regions. Int J Soc Welfare 2020; 29:255-69. Available from: https://doi.org/10.1111/ijsw.12419

4. Davy C, Kite E, Aitken G, Dodd G, Rigney J, Hayes J, et al. What keeps you strong? A systematic review identifying how primary health-care and aged-care services can support the well-being of older Indigenous peoples. Australas J Ageing 2016; 35:90-7. Available from: https://doi.org/10.1111/ajag.12311

5. Smith K, Yaqoot F, Knight S. Are primary healthcare services culturally appropriate for Aboriginal people? Findings from a remote community. Aust J Prim Health, 2017; 23(3):236-42. Available from: https://doi.org/10.1071/py16110

6. Dagsvold I, Møllersen S, Blix BH. Clinicians' assumptions about Sami culture and experience providing mental health services to Indigenous patients in Norway. Transcult Psychiatry, 2020; 57(2):363-74. Available from: https://doi. org/10.1177/1363461520903123

7. Ekman SL, Wahlin TB, Norberg A, Winblad B. Relationship between bilingual demented immigrants and bilingual/ monolingual caregivers, Int J Aging Hum Dev, 1993; 37(1):37-54. Available from: https://doi.org/10.2190/NU87-FGPO-CNEU$\underline{\mathrm{DCH} 5}$ 
8. Heikkilä K, Sarvimäki A, Ekman SL. Culturally congruent care for older people: Finnish care in Sweden, Scand J Caring Sci 2007; 21(3):354-61. Available from: https://doi.org/10.1111/j.14716712.2007.00480.x

9. Mehus G, Andersdatter Bongo B, Moffitt P. Important factors when communicating with Sami patients about health, illness and care issues. Nord Nurs Res 2018; 8(4):303-16. Available from: https://doi.org/10.18261/issn1892-2686-2018-04-04

10. Boge J. The inferior position of the Sámi language in a bilingual nursing home in Norway. J Multiling Multicult Dev. 2020;41(3):195-205. Available from: https://doi.org/10.1080/01 434632.2019.1597875

11. Ness TM, Söderberg S, Hellzén O.'The same care providers over time who make individual adjustments and have competence' older South Sami people in Sweden's expectations of home nursing care; Scand J Caring Sci, 2019;34(1),181-9. Available from: https://doi.org/10.1111/scs.12719

12. Ness TM, Söderberg S, Hellzén O. 'Contr adictions in having care providers with a South Sami background who speak South Sami': older South Sami people in Sweden's expectations of home nursing care. Scand J Car Sci. 2019;34(2),436-45. Available from: https://doi.org/10.1111/scs.12747

13. Ness TM, Hellzen O, Enmarker I. "Struggling for independence": The meaning of being an oldest old man living in a rural area. Interpretations of oldest old men's narrations. Int J Qual Stud Health Well-being. 2014; 9(1):23088. Available from: https://doi.org/10.3402/ahw.v9.23088

14. Ness TM, Hellzén $O$, Enmarker I. "Embracing the present and fearing the future": the meaning of being an oldest old woman in a rural area. Int J Qual Stud Health Well-being. 2014; 9(1):25217. Available from: https://doi.org/10.3402/ghw, v9.25217

15. Patton $M Q$. Qualitative research \& evaluation methods: integrating theory and practice. $4^{\text {th }}$ edn. 2015. London: Sage Publications Inc.

16. Saemiensijte. Om sørsamer. Saemiensijte. 2021. [cited 2021 Mar 02] Available from: https://saemiensijte.no/om-sorsamer/

17. Samer.se. Undated. How many Sami are there? Östersund: Samiskt informationscentrum. [cited 2021 Mar 02] Available from: http://www.samer.se/samernaisiffror

18. Sammalahti P. The Saami languages: An introduction. Kárášjohka: Davvi Girji; 1998

19. Samediggi. Blankett för anmälan till sameröstlängden Samediggi. 2018. [cited 2018 Nov 30] Available from: https://www.samediggi.se/samerostlangden

20. Kvale S, Brinkmann S. Den kvalitativ forskningsintervjun. Lund: Studentlitteratur; 2014.

21. Graneheim UH, Lundman B. Qualitative content analysis in nursing research: concepts, procedures and measures to achieve trustworthiness. Nurse educ today; 2004; 24(2),105112. Available from: https://doi.org/10.1016/j.nedt.2003.10.001

22. World Medical Association. WMA Declaration of HelsinkiEthical Principles for Medical Research Involves Human Subjects. 2018.

23. Worrall G, Knight J. Continuity of care for older patients in family practice: how important is it? Can Fam Physician. 2006;52:754-5.

24. Russell D, Rosati RJ, Rosenfeld P, Marren JM. Continuity in home health care: is consistency in nursing personnel associated with better patient outcomes? J Healthc Qual. 2011; 33(6):33-9. Available from: https://doi.org/10.1111/j.1945-1474.2011.00131.x
25. Gjevjon ER. Continuity in long-term home health care: perspectives of managers, patients and their next of kin [dissertation]. 2014.

26. Gjevjon ER. Continuity of home care - difficult conditions, but good opportunities. Tidsskrift for omsorgsforskning; 2015; 1(1):18-26.

27. Sparbel KJH, Anderson MA. Integrated literature review of ontinuity of care: part 1, conceptual issues, J Nurs Scholarsh; 2000; 32(1):17-24. Available from: https://doi.org/10.1111/ j.1547-5069.2000.00017.x

28. Saultz JW, Albedaiwi W. Interpersonal continuity of care and patient satisfaction: a critical review. Ann Fam Med. 2004;2(5):445-1. Available from: https://doi.org/10.1370/afm.91

29. Hsiao CJ, Boult C. Effects of quality on outcomes in primary care: a review of the literature. Am J Med Qual. 2008; 23(4):302-10.

30. McDonald A, Lolich L, Timonen V, Warters A. "Time is more important than anything else": tensions of time in the home care of older adults in Ireland. Int J Care Caring. 2019; 3(4):501-15. Available from: https://doi.org/10.1332/23978821 9X15622468259858

31. D'Errico EM. RN continuity and end-result outcomes in home health care. Unpublished doctoral dissertation. University of California. Los Angeles. 2006.

32. Tuominen L, Leino-Kilpi H, Meretoja R. Expectations of patients with colorectal cancer towards nursing care- a thematic analysis. Eur J Oncol Nurs. 2020; 44:101699-101699. Available from: https://doi.org/10.1016/j.ejon.2019.101699

33. Uno M, Tsujimoto T, Inoue T. Perceptions of nurses in Japan toward their patients' expectations of care: a qualitative study. Int J Nurs Sci. 2017; 4(1):58-62. Available from: https://doi.org/10.1016/j.ijnss.2016.12.005

34. From I, Johansson I, Athlin E. The meaning of good and bad care in the community care. Int J Older People Nurs. 2009; 4(3)156-65. Available from: https://doi.org/10.1111/j.17483743.2008.00156.x

35. Dale B, Sævareid HI, Kirkevold M, Söderhamn O. Older homeliving patients' perceptions of received home nursing and family care. Nordisk sygeplejeforskning [Nordic Nursing Reseach], 2011;1(3):219-34. Available from: https://www.idunn.no/ nsf $/ 2011 / 03 /$ art02? languageid $=2$

36. Mehus G, Bongo BA, Engnes JI, Moffitt PM. Exploring why and how encounters with the Norwegian health-care system can be considered culturally unsafe by North Sami-speaking patients and relatives: a qualitative study based on 11 interviews. Int J Circumpolar Health, 2019; 78:1 Available from: https://doi.org/10.1080/22423982.2019.1612703

37. Ness TM, Enmarker I, Hellzen O. Experiences of being old and receiving home nursing care: older South Sámi narrations of their experiences - an interview study. Open J Nurs; 2013; 3:1-7. Available from: https://doi.org/10.4236/ojn.2013.31001

38. Novic $G$. Is there a bias against telephone interviews in qualitative research? Res Nurs Health. 2006; 31:391-8. Available from: https://doi.org/10.1002/nur.20259 